\title{
The effect of using a corpus on Iranian EFL learners' writing: Focus on grammatical accuracy and attitude
}

\author{
Khalili, Elahe $\measuredangle$ \\ Sobhe Sadegh Institute of Higher Education, Iran (Ekhalili37@yahoo.com) \\ Rezvani, Ehsan \\ Isfahan (Khorasgan) Branch, Islamic Azad University, Isfahan, Iran(Rezvani_ehsan_1982@yahoo.com)
}

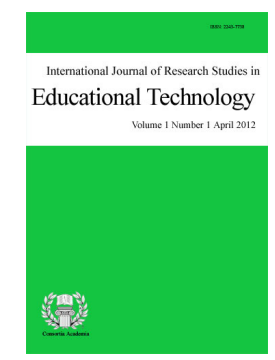

ISSN: 2243-7738 Online ISSN: 2243-7746

OPEN ACCESS

\section{Abstract}

An increasing number of recent studies have applied the insights and methodologies of corpus linguistics to second language (L2) writing pedagogy and research. This study examined the effects of corpus use on how it affects their development of L2 grammatical accuracy Iranian EFL learners in writing. Additionally, the learners' attitude toward using corpus for writing was investigated in this study. Participants were 60 upper-intermediate language learners of English who were divided into two homogenous groups according to the results of an Oxford Placement Test (OPT). Then, all the participants of two groups were given a pretest, the result of which assured the homogeneity of the groups with regard to their writing skill. The first experimental group passed the course in a laboratory and wrote their essays on a computer and checked them by using corpus. In this study Grammarly was used as a corpus tool. The second experimental group used online dictionaries to write. Also, students of the second experimental group wrote their writings conventionally, on paper and it was the teacher who checked their essays. Finally, participants sat for the post-test after the treatment. Findings revealed that there was a significant effect of using corpus on learners' grammatical accuracy in writing. As for the second question, there was a positive attitude toward using corpus. Findings of this study may inspire teachers to benefit from these types of writing activities.

Keywords: corpus; concordance; attitude; writing accuracy 


\section{The effect of using a corpus on Iranian EFL learners' writing: Focus on grammatical accuracy and attitude}

\section{Introduction}

Developments in Information and Communications Technologies have not just simply provided new ways of teaching the traditional literacies of reading and writing; but have themselves become a new type of literacy, producing a rapidly changing learning environment and presenting a major challenge to learners, teachers and researchers. The concept of literacy now includes not only the knowledge and skills which are traditionally associated with that concept but also the ability to select, evaluate and use the electronic tools and resources appropriate for the activity which is being undertaken. It is not surprising that much of the literature relating to these new literacies focuses on the use of the World Wide Web (Warschauer, 1999; Cope \& Kalantzis, 2000; Kasper, 2000; Murray, 2000; Richards, 2000), and yet it is clear to those researching in the area of learner access to corpora that for language learners at an advanced level, corpus consultation skills may form a particularly important new literacy. Despite a number of recent studies (Cobb, 1997; Bowker, 1998; Kennedy \& Miceli, 2001), there is a dearth of empirical studies which could form the basis of developments in language pedagogy.

In recent years, interest in applying the results of corpus research to second language (L2) pedagogy has been growing. Corpus research gathers authentic uses in a wide variety of sources in such a way that learners can study specific language uses within the corpus. For instance, a learner of English who wants to use the word "believe" in an essay might be confused about which words best collocate or link, with that word. In order to use different links of the word, he/she can connect to a corpus and see its different collocations. As learner types the word "believe", corpus database show it as a reference in its different usages and it is also called as a "concordance program." Concordance program makes a list of example by the keyword which is called concordance.

The above-collected information is technically called as a "concordance output." In order to see the different usages of a keyword in different sentences or concordances, learners use corpora and study this information. Additionally, corpus database can produce a second type of output known as "collocate output" which indicates how a keyword collocated, or linked, with specific words in a larger corpus.

While some studies have been interested in spoken corpora (e.g., Simpson \& Swales, 2001), there has been a desire for corpora in written discourse, especially on the analysis of literary texts (Hockey, 2001). Regarding their emphasis on textual analysis and descriptions of written language in use, corpus-based studies are especially considered the teaching of reading and writing skills and academic literacy development (Flowerdew, 2002). In this vein, Jabbour (2001) claims that "a corpus approach befits teaching second language reading and writing, since both activities are text oriented and make use of words and word combinations, or lexical patterns, within the confines of discourse" (p. 294). In other words, a corpus approach provides meaningful input in language learning, especially in written discourse. Although there has been an interest in teaching and learning of writing in another language, the main concern was of syntax, punctuation, style, vocabulary development, etc. of the language domain. It is clear that most of the L2 writers, especially the one who is below the advanced level, want to develop their writing by improving their knowledge of linguistic resources which are necessary for an effective writing. A corpus is now seen as a primary contributor of these resources because, as Tao (2001) observes, of its "potential to make explicit the more common patterns of language use" (p. 116).

It is interesting to mention that one of the main rules of the corpus approach in the description of the language is the interrelationship between vocabulary and grammar rather than distinctive relation from each other (Halliday, 1992; Sinclair, 1991). Regarding the link between vocabulary and grammar, also known as lexica-grammar, there is an emphasis on the co-occurrence or most frequent combinations of words, i.e., 
The effect of using a corpus on Iranian EFL learners' writing: Focus on grammatical accuracy and attitude

“collocation”, (Biber \& Conrad, 2001; Conrad, 2000).

One of the main concerns in the traditional way in writing is that teachers and textbook writers have provided language input for students. Biber (2001) points out that "these decisions have usually been based on the author's gut-level impressions and anecdotal evidence of how speakers and writers use language" (p. 101). Teachers, too, may depend on their own notions of which language items are most useful for students to learn. Biber (2001) goes on to explain that "empirical analyzes of representative corpora provide a much more solid foundation for descriptions of language use", (p. 101).

While there are positive aspects to the inclusion of a corpus component, some learners may have difficulty in acquiring the skills needed to experience it, and not all students have access to the technology necessary to employ it. Then, too, some concordance programs are particularly sophisticated and produce language data in formats difficult to interpret. Learners may feel overwhelmed as well as powerless in the face of such complex looking linguistic input. Johns (1994) also mentions the problem of trainability; that is, there is uncertainty as to whether and to what extent students can be trained to use corpus technology. In addition, Cobb (1997) has commented on the amount of time necessary for students to become accustomed to the new technology-time that could well be spent on other, more conventional and time-tested classroom practices.

Furthermore, many researches consider the benefits of corpus-based activities, and only a few empirical studies have investigated student responses to corpus use. Some supplementary findings suggest that students have a positive attitude toward vocabulary learning while using corpora (Cobb, 1997; Thurstun \& Candlin, 1998). In Thurstun and Candlin's pilot study (1998), for example, participants showed a positive view toward this innovation in vocabulary teaching. However, they also reported some negative reactions, such as, "some students were puzzled by the cut-off sentences of the one-line concordances and daunted by the difficulty of the authentic academic texts" (p. 271). One student complained that "there are [too] many exercises for just three words"' (p. 277). To sum up, the main difficulties in using corpus is due to the students' attitude. There might be negative reaction as a result of lack of knowledge in using corpus as it is a new innovation.

In summary, several gaps from the existing literature motivated this study. Most important of all, further research needs to examine how corpus technology affects students' development of competence as L2 writers as well as their writing experiences. The development of learner-specific descriptions in corpus use and its evaluation would also be valuable. Also, there is little research on the teacher's integration of a corpus component into L2 writing instruction. In order to understand how this new technology affects and contributes to students' L2 writing, we need to look at the phenomenon in depth in teaching and learning practice.

\section{Literature review}

In the field of corpus linguistics, the interest in corpus research in the second language (L2) pedagogy has been growing. Here, corpus research means that language learners can study a target language usage with a large amount of authentic language data (Yoon \& Hirvela, 2008). Many researchers have examined the effectiveness of corpus research and students' attitudes toward corpus use in the learning. Students also showed a positive attitude toward on-line practice, and they thought that the on-line materials helped them to understand of connector usage. This study shows that corpora use can improve grammatical pointers and help the student develop their writing skills. It does not, however, investigate whether students can independently identify and correct errors.

Sun's (2000) study evaluated 37 Taiwanese EFL college students' responses to corpus-based activities. Through a survey after a 3-week on-line corpus lesson, he found that most students liked corpus-based learning, especially authentic language texts. In addition, they felt that the corpus-use helped improve language awareness and sensitivity individual words or phrases. Sun's study focused more on the student response toward the corpus as a learning tool, but he did not show how the corpus could actually be incorporated in traditional language classes. 
Many researchers have emphasized corpus training in preparation for successful corpus use (Cobb, 1997; Flowerdew, 1996; Kennedy \& Miceli, 2001). Also, difficulties encountered when acquiring on-line corpus skills have been examined. Granath (2009) explained how students become skilled corpus users and discussed the problems that arise during training. He mentioned problems involving language proficiency, limited computer skills, and with students formulating their own queries and their difficulties in interpreting corpus data. $\mathrm{He}$ concluded that significant efforts on the part of the teachers, as well as enough time for training, were needed to help students acquire the corpus skills.

John (1994) also indicated the training difficulties in corpus study. That is, not all students can access and interpret the language data, and a certain amount of time is necessary for them to become familiar to the technology for corpus study. In addition, Thurstun and Candlin (1998) found that some learners were afraid of the difficulty of consulting authentic texts and that they complained about the huge amount of available data on a word. The two most important decisions concerning the corpus to be provided concern the nature of the texts and the number of words. It was decided to provide a corpus of texts on topics similar to those studied in this part of the course, which could be updated from year to year. As the students' task is to write a commentary on a text, the corpus would ideally contain similar commentaries written by native speakers, but this was not possible. Therefore, it was decided to include texts in English relating to the history and development of its language and to current issues relating to the language, written by educated and informed native speakers, thus providing the students with models of well-written contemporary Standard English.

Watson Todd (2001), meanwhile, showed overall positive results in a study where 25 Thai post-graduate students in an English language support course induced rules from self-selected concordances and applied those rules to self-correction of the errors in their writing. The participants' writing samples were marked by the researcher for lexical items that were misused. The participants then chose one of the marked lexical errors, searched for instances of the lexical item on the Internet, selected 10 concordance lines, extracted the rules/patterns from those 10 concordances and corrected the lexical errors they had made applying those rules. The results were that a mean of 7.78 concordance incidences (out of 10) matched the induced patterns and that out of a total of 23 lexical items, 18 were validly corrected. The researcher identified the number of parts of speech and the number of meanings that a specific lexical item can take as factors that influence learners' ability to induce valid rules and apply them to self-error correction. One of the factors that helped produce the overall positive results here can be explained by Hyland's (2003) caveat about research approaches to corpora discussed above. The participants in the study selected only 10 incidences that they could comprehend and therefore could avoid having to deal with "overexposure to concordance lines" from the Internet. In addition, they were given opportunities to make immediate use of induced knowledge by applying it back to the correction of their errors.

The studies reviewed above show the importance of student training in concordance when combining a corpus-based approach into the L2 writing/EAP class. Kennedy and Miceli (2001) give a sense of how gradual and guided training in learner corpus investigation can be done as part of a writing course. The researchers took what they call "apprenticeship" approach to training intended to "promote learning by example and by experience" (p. 79). The students practiced using a corpus specially designed by the researchers as a problem-solving tool when revising their own writing and also as a "treasure hunting" tool (p. 79) to find typical expressions or patterns used for specific situations. To evaluate how successful the students would be at the extracting information they need from the corpus without the help of a teacher, the researchers gave the students two texts to revise using the corpus. The results revealed that although the students made many successful investigations, they were ignorant of "common pitfalls and techniques for avoiding them" (p. 81). The authors concluded that their apprenticeship training was not sufficient to equip the students with needed corpus investigation skills. This study aimed to fill the gap of using corpus by answering the following research questions:

$>$ Does using corpus significantly improve Iranian EFL learners' grammatical accuracy in writing? 
The effect of using a corpus on Iranian EFL learners' writing: Focus on grammatical accuracy and attitude

$>\quad$ What are Iranian EFL learners' attitudes toward using corpus as a reference tool for improving their writing proficiency?

$>\quad$ Is there a significant difference between the effects of using corpus vs. dictionary on Iranian EFL learners' grammatical accuracy in writing?

\section{Methodology}

\subsection{Participants}

This study was conducted with a random sample of 100 (male and female) upper-intermediate EFL learners whose ages ranged between 18 and 25 at Jahad Daneshgahi language school in Isfahan, Iran. In order to make sure about their homogeneity, they were given an Oxford Placement Test (OPT). The researcher selected participants whose score range fell one standard deviation above and below the mean (i.e. mean \pm 1 ). This being so, 60 students who met this criterion were chosen to participate in this study. They were divided randomly into two experimental groups involving 30 students each. The first experimental group met three times per week for one hour while the second one met twice per week for one and half hour.

\subsection{Instruments}

Grammarly.com Website - Grammarly.com is a web-based corpus analysis tool which was founded by Alex Shevchenko and Max Lytvyn, intended to address the requirements for developing written discourse. It is easy to handle enabling technically less competent learners to exploit corpora just like browsing web pages. The functions provided by Grammarly.com are including grammar checker that can analyze general, business, academic, technical, creative and casual writing, contextual spell checker which determines the appropriate spelling of a word as it is used in a sentence; thus, it finds misspelled words and also identifies correctly spelled yet incorrectly used words, checking grammar and syntax in an online Grammarly Handbook, Google Chrom extension, which spell check and grammar check as you type online.

Grammarly is a writing enhancement developed by Grammarly, Inc., and launched in 2009. It provides more than 250 rules for a writer adherence which contains proofreading and plagiarism-detection and finally provides users with a list of possible errors for correction. During its text review, Grammarly presents potential errors one at a time, with commonly confused words or faulty sentences highlighted in light red and a text box below offering an explanation that provides good and bad examples and suggests corrections. Grammarly also provides citations when it detects plagiarism Users can click on a "thumb up" or "thumb down" icon to let Grammarly know whether the result was helpful. It is interesting to mention that in the 2013 Best Online Grammar Checker Comparisons and Reviews, Grammarly won the Top Ten reviews Gold Award, with a rating of 8.88 .

Compared with other online corpus, Grammarly has its own advantages: Firstly, EFL learners can have easy access to multiple corpus examples. Just as Frankenberg-Garcia (2012) stated, multiple concordances are more useful than dictionary definitions in helping participants to correct the use of words that they knew but frequently misused. And the research also proved that multiple corpus examples seem to help more consistently than single corpus examples in autonomous error correction. Thus, multiple corpus examples presented by Grammarly can help EFL learners better in correcting errors than a single online corpus. Secondly, the parallel corpora can function as a dictionary when learners are confused about some new words in the concordance lines or unable to express what they want to convey in the target language.

The following figure clearly explains the web site. 


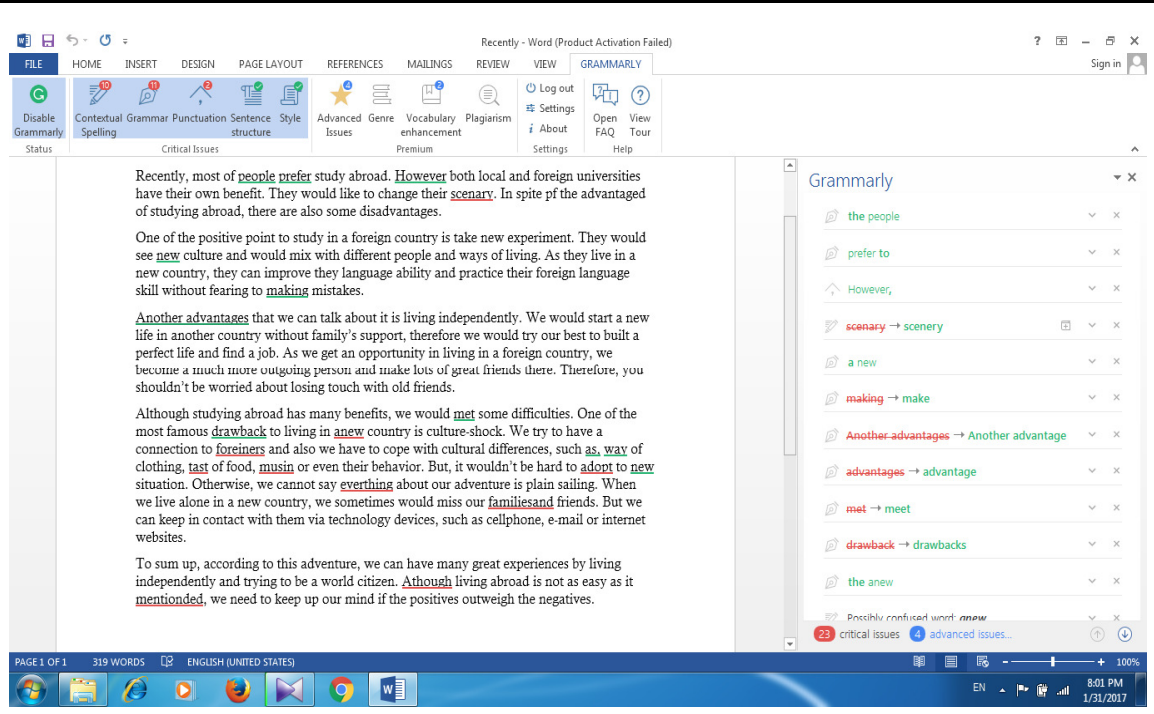

Figure 1. Writing Sample and Grammarly Suggestions

Online Dictionary - Traditionally, learners correct the lexica-grammatical errors by referring to dictionaries. In dictionaries, learners can get not only definitions, collocations, synonyms, antonyms and usages, but also the grammatical information of target words. Most learners prefer an online dictionary to a paper dictionary for quick reference in this technology-based era. Thus, we chose the online dictionary (www.learnersdictionary.com) for the second experimental group to correct errors in their articles. This dictionary not only provides functions of the monolingual dictionaries but also has the advantages of bilingual dictionaries.

\subsection{Procedure}

The following procedure was adapted for the present study.

Administration of the Pre-test - As noted earlier, 60 homogenized students were selected to be the participants of this study. At first, the instructor gave a pretest to all two groups for which they wrote an essay about a certain topic that the teacher provided.

Treatment - After the pretest, the first experimental group passed a course which took two months. During the course, instructor gave different topics to the students of the first experimental group so that they wrote an essay for each subject. The experimental group wrote their writing on their computers. Each student worked with a computer and had direct access to the corpora. They installed grammarly as a corpus database on their computers and as they wrote their essays on the Word Office program, they enabled it and it is the corpus that solved students' problems. There are two toolbars on the page which is presenting the text's problems. The toolbar above the page checks the numbers of the problems in contextual spelling, grammar, punctuation, sentence structure and style of the written text. Meanwhile, the other toolbar which is on the right of the page showes the grammatical problems in red and suggestes the correct form in green. As students corrected them, the mistakes disappeared on the right toolbar automatically and green ticks was a sign in which there is any mistakes. Additionally, the other experimental group used an online dictionary to improve their writing as they were writing about the same topics as the students in the first experimental group, if it was needed. They wrote their writings conventionally, receive no tools for improving their writing. In other words, they wrote their essays on the paper and the instructor checked their writings and solved the problems.

Administration of the Post-test - After the treatment period, participants sat for a posttest in which they wrote another essay with a different topic of the pretest to know whether there was any improvement in their writing or not. As this study aimed to investigate learners' attitude toward using corpus, participants filled a 6-point Likert scale questionnaire to show the degree of agreement on using corpus in developing their writing proficiency. It was mentioned that participants of the first experimental group used corpus but as they were not 
The effect of using a corpus on Iranian EFL learners' writing: Focus on grammatical accuracy and attitude

familiar with it, the instructor introduced the course into two steps:

\section{Step 1 training: From Dependent to Independent}

A teacher-friendly way to encourage students to focus more on writing proficiency is to train them in methods to query online corpora. Considering that all the participants did not have prior experience in consulting corpus, we divided the training into two stages. At the beginning, the independent step; in which students get help of the instructor, was adopted. As they were not familiar with the corpus, instructor started to introduce the website (Grammarly) to the students in detail. When learners are more skilled in doing the task, the more divergent, or independent step; in which students work individually, assigned to them. Thus, the instructor observed learners directly at this stage to solve their problems in using the corpus databases and ask them to print their both writing. The first one which included their errors in highlight and the second one that they solved their grammatical problems by utilizing the corpus websites. For knowing their development in writing, it was important that students deliver their both writings in a printed form which makes the analyzing easier.

\section{Step 2: Questionnaire}

A 6-point Likert scale questionnaire used in this study. The questionnaire included 42 items to which the respondents responded to show their degree of agreement from strongly disagree to strongly agree. They also had an alternative option, "'no opinion."' The majority of items were adapted from questionnaires in Yoon and Hirvela (2004) and Huang (2014). The researcher designed the remaining items, especially for this study. These items were divided into three parts. The first part was about the positive sides of corpus use in improving learners' writing accuracy, the second part was about the difficulties in using corpus and the third part was about the overall evaluation of corpus use in writing. All items were presented in English. At the end of this term, questionnaires were delivered to the first experimental group about their perceptions of using corpus for improving their writing proficiency.

\subsection{Data Analysis}

In order to answer the first research question of the study, paired-sample t-test was used to examine the development of the learners' grammar accuracy in writing of the both groups before and after the treatment sessions (performance of learners in pre-test and post-test). Additionally, to answer the third research question, an independent-sample t-test was run to compare the effect of using corpus and online dictionary in learners' writing grammar accuracy. However, to answer the second research question, researcher defined each question as one item and then the defined scores for each item were statistically analyzed using the Statistical Packages for Social Sciences (SPSS).

\section{Data Analysis and Results}

When all the data were gathered, the outcomes of each measure were fed into SPSS software to compare the performance of learners within and between groups. It should be mentioned that a further comparison was done on the outcomes of the second experimental group in order to make sure that the differences between participants' performance in experimental groups is due to the treatment procedures. The following parts are devoted to the findings of the study.

\subsection{Findings of the First Research Question}

The first research question addressed the influence of using corpus in improving Iranian EFL learners' writing grammatical accuracy. To make a response to this question, a null hypothesis was formulated which will be examined in this section.

Hypothesis 1: Using corpus does not significantly improve Iranian EFL learners' writing proficiency. 
Khalili, E., \& Rezvani, E.

In order to examine the effect of using corpus on learners' writing grammatical accuracy, a paired-sample t-test was conducted. In this case, the learners' performance of the first experimental group was compared in pre-test and post-test. T-test result are shown in the following table.

Table 1

Paired-Samples Statistics Comparing Pre-and Post-test Scores of the Experimental Group

\begin{tabular}{llllcc}
\hline & & Mean & N & SD & Std. Error Mean \\
\hline Pair 1 & Pretest & 15.35 & 60 & 1.21 & .15 \\
& Posttest & 16.88 & 60 & 1.14 & .14 \\
\hline
\end{tabular}

As it can be seen, in the table 1, there was an increase on learners' writing grammatical accuracy of the first experimental group from pre-test $(M=15.35, S D=1.21)$ to post-test $(M=16.88, S D=1.14)$. Moreover, as it is seen in table 2 , probability value for experimental group is $.000<.05$, which indicates a significant difference between learners' scores in pre- and post-test. Consequently, corpus data-based was found to exert a significant effect on learners' writing proficiency and the first null hypothesis was rejected.

Table 2

Paired-Sample T-Test

\begin{tabular}{lcccccr}
\hline \multirow{2}{*}{ Mean } & \multirow{2}{*}{ SD } & \multirow{2}{*}{ Std. Error Mean } & \multicolumn{2}{c}{$95 \%$ Confidence Interval of the Difference } & \multirow{2}{*}{ Sig. } \\
\cline { 4 - 5 } & & Lower & Upper & & \\
\hline-1.52 & 1.69 & .21 & -1.96 & -1.09 & 59 & .000 \\
\hline
\end{tabular}

\subsection{Findings of the Second Research Question}

This study also aimed to investigate the effect of using corpus as a reference tool on learners' attitude toward using corpus to improve their writing. In order to analyze the attitude of the learners, we gave a questionnaire of the participants. As mentioned above, the questionnaire included 42 questions which was divided into three parts. The first part was about the positive side of using corpus in improving learners' writing proficiency. As it was noted, the first fourteen questions belonged to the first part. The obtained results will be presented in the following order.

Table 3

Student Assessment of the Usefulness of the Corpus

\begin{tabular}{|c|c|c|c|c|c|c|c|}
\hline Items & 1 & 2 & 3 & 4 & 5 & 6 & $\mathrm{~N}$ \\
\hline The searching technique was easy to learn & 0 & 0 & 0 & 0 & 21.3 & 77 & 0 \\
\hline $\begin{array}{l}\text { The practice sessions in the computer lab were } \\
\text { helpful for learning the technique }\end{array}$ & 0 & 0 & 0 & 8.2 & 24.6 & 65.6 & 0 \\
\hline $\begin{array}{l}\text { It is easy to construct prototype strings by use } \\
\text { of concordance/collocate output }\end{array}$ & 0 & 0 & 13 & 44.3 & 41 & 0 & 0 \\
\hline $\begin{array}{l}\text { Constructing prototype is a useful experience } \\
\text { for language learning }\end{array}$ & 0 & 0 & 0 & 37.7 & 60.7 & 0 & 0 \\
\hline $\begin{array}{l}\text { I feel confident in constructing prototype } \\
\text { strings }\end{array}$ & 0 & 9.8 & 29.5 & 59 & 0 & 0 & 0 \\
\hline $\begin{array}{l}\text { I use the prototype strings that the teacher gave } \\
\text { us as a reference when I write }\end{array}$ & 0 & 18 & 9.8 & 18 & 52.5 & 0 & 0 \\
\hline $\begin{array}{l}\text { The corpus is more helpful than a dictionary for } \\
\text { my English writing }\end{array}$ & 0 & 0 & 0 & 11.5 & 57.4 & 29.5 & 0 \\
\hline $\begin{array}{l}\text { Using the corpus is helpful for learning the } \\
\text { collocates }\end{array}$ & 0 & 0 & 0 & 19.7 & 49.2 & 29.5 & 0 \\
\hline
\end{tabular}


The effect of using a corpus on Iranian EFL learners' writing: Focus on grammatical accuracy and attitude

Table 3 ... continued

\begin{tabular}{|c|c|c|c|c|c|c|c|}
\hline Items & 1 & 2 & 3 & 4 & 5 & 6 & $\mathrm{~N}$ \\
\hline $\begin{array}{l}\text { Using the corpus is helpful for learning the } \\
\text { usage of vocabulary }\end{array}$ & 0 & 0 & 0 & 14.8 & 41 & 42.6 & 0 \\
\hline $\begin{array}{l}\text { Using the corpus is helpful for learning the } \\
\text { usage of phrases }\end{array}$ & 0 & 11.5 & 9.8 & 55.7 & 21.3 & 0 & 0 \\
\hline $\begin{array}{l}\text { Using the corpus is helpful for learning } \\
\text { grammar }\end{array}$ & 0 & 0 & 0 & 24.6 & 55.7 & 18 & 0 \\
\hline $\begin{array}{l}\text { Using the corpus improved my grammar } \\
\text { accuracy in writing }\end{array}$ & 0 & 0 & 11.5 & 16.4 & 45.9 & 24.6 & 0 \\
\hline $\begin{array}{l}\text { Using the corpus improved my English writing } \\
\text { skill }\end{array}$ & 0 & 0 & 13 & 23 & 47.5 & 14.8 & 0 \\
\hline $\begin{array}{l}\text { Using the corpus improved my English } \\
\text { academic writing ability }\end{array}$ & 0 & 0 & 0 & 14.8 & 50.8 & 32.8 & 0 \\
\hline
\end{tabular}

Note. Values are in percentage.

Table 3, shows the student assessment of the usefulness of the corpus which presents all the students' answers in percentage. As it is seen, in the first question all the participants showed a positive view about using searching technique $(5=21.3 \%, 6=77 \%)$. Therefore, all the learners responded the first question in agree and strongly agree and the researcher put zero percent for other points. In general, the students reported positive feelings about corpus use relative to writing. It is notable that learners mostly agreed in using corpus for their English writing and they believed that corpus was more helpful than a printed-form dictionary $(4=11.5 \%, 5=$ $57.4 \%, 6=29.5 \%)$. Moreover, the result indicated that corpus was a helpful technique for learning collocates (4= $19.7 \%, 5=49.2 \%, 6=29.5 \%$ ). As we can see, 49 percent of the learners agreed about the helpfulness of using corpus in collocates' learning.

Another point which was considered in the present study is the learners' improvement in their writing grammatical accuracy. At this point, most of the participants agreed in using corpus $(5=45.9 \%)$. All things considered, there was a positive side for learners' writing improvement by using corpus. Turning to the second part of the questionnaire, the second eleven questions belonged to the second part of the questionnaire. The following table presents the results of the second part.

\section{Table 4}

Student problems/difficulties in corpus use

\begin{tabular}{|c|c|c|c|c|c|c|c|}
\hline Items & 1 & 2 & 3 & 4 & 5 & 6 & $\mathrm{~N}$ \\
\hline $\begin{array}{l}\text { I have some difficulty in using the corpus due } \\
\text { to limited access to computer/Internet }\end{array}$ & 0 & 18 & 45.9 & 21.3 & 13 & 0 & 0 \\
\hline $\begin{array}{l}\text { I have some difficulty in using the corpus due } \\
\text { to the speed of Internet connection }\end{array}$ & 0 & 0 & 0 & 27.9 & 70.5 & 0 & 0 \\
\hline $\begin{array}{l}\text { I have some difficulty in using the corpus due } \\
\text { to time and effort spent on analyzing the data }\end{array}$ & 0 & 54 & 24.6 & 19.7 & 0 & 0 & 0 \\
\hline $\begin{array}{l}\text { Difficulty in using the corpus due to unfamiliar } \\
\text { vocabulary on concordance/collocate output }\end{array}$ & 0 & 52.5 & 29.5 & 16.4 & 0 & 0 & 0 \\
\hline $\begin{array}{l}\text { Difficulty in using the corpus due to cut-off } \\
\text { sentences in concordance output }\end{array}$ & 0 & 18 & 26.2 & 37.7 & 16.4 & 0 & 0 \\
\hline $\begin{array}{l}\text { I have some difficulty in using the corpus due } \\
\text { to too many sentences in concordance output }\end{array}$ & 50.8 & 34.4 & 13 & 0 & 0 & 0 & 0 \\
\hline $\begin{array}{l}\text { I have some difficulty in using the corpus due } \\
\text { to the limited number of sentences in } \\
\text { concordance output }\end{array}$ & 0 & 57.4 & 24.6 & 16.4 & 0 & 0 & 0 \\
\hline
\end{tabular}


Khalili, E., \& Rezvani, E.

Table 4 ... continued

\begin{tabular}{|c|c|c|c|c|c|c|c|}
\hline Items & 1 & 2 & 3 & 4 & 5 & 6 & $\mathrm{~N}$ \\
\hline $\begin{array}{l}\text { I have some difficulty in analyzing } \\
\text { concordance output }\end{array}$ & 0 & 75.4 & 23 & 0 & 0 & 0 & 0 \\
\hline $\begin{array}{l}\text { I have some difficulty in analyzing collocate } \\
\text { output }\end{array}$ & 27.9 & 70.5 & 0 & 0 & 0 & 0 & 0 \\
\hline $\begin{array}{l}\text { I have some difficulty in performing the search } \\
\text { technique }\end{array}$ & 0 & 29.5 & 9.8 & 18 & 0 & 0 & 41 \\
\hline $\begin{array}{l}\text { The real texts in the corpus are too difficult to } \\
\text { understand }\end{array}$ & 19.7 & 42.6 & 9.8 & 0 & 0 & 0 & 26.2 \\
\hline
\end{tabular}

Note. Values are in percentage.

Table 4, provides an intriguing look at some specific areas of possible concern or difficulty with respect to corpus use. Overall, it can be seen that for the most part, the mean scores of student reactions to the problems/ difficulties in corpus use clustered in disagree and somewhat disagree (2 and 3 score range respectively), indicating that, on the whole, students found corpora not very difficult to use.

In terms of difficulties or perhaps frustration, with respect to the amount of time necessary to analyze data provided by corpora should be noted, learners mainly disagreed $(2=54 \%)$. However, to concentrate the difficulties of using corpus among unfamiliar vocabularies, participants showed 52 percent of disagreement. It is interesting to mention that the participants' strongly disagreed about difficulties due to many sentences of concordance output which rose considerably $(1=50.8 \%)$. Due to the participants' difficulties in analyzing concordance output and collocate output, there was a considerable increase in the degree of disagreement $(2=$ $75.4 \%$ and $2=70.5 \%$ respectively). Moreover, it is remarkable that most of the learners had no opinion in performing the search technique by the percent of 41 .

With regard to the above results, this is a subtle reminder that writing teachers should not assume that upper intermediate students automatically have advanced-level computer skills, and that time spent in class illustrating how to use corpora can be fruitful. Considered all the benefits and difficulties of using corpus through the participants view, the overall evaluation of corpus use in writing will be presented in the following table.

Table 5

Students' overall evaluations of corpus use in L2 writing

\begin{tabular}{|c|c|c|c|c|c|c|c|}
\hline Items & 1 & 2 & 3 & 4 & 5 & 6 & $\mathrm{~N}$ \\
\hline I often use the corpus by my own choice & 0 & 47.5 & 0 & 34.4 & 16.4 & 0 & 0 \\
\hline $\begin{array}{l}\text { I understand the purpose of using the corpus in } \\
\text { this course }\end{array}$ & 0 & 0 & 0 & 21.3 & 45.9 & 31 & 0 \\
\hline $\begin{array}{l}\text { I want to use the corpus in my next EFL } \\
\text { writing course too }\end{array}$ & 0 & 0 & 0 & 21.3 & 57.4 & 0 & 19.7 \\
\hline $\begin{array}{l}\text { When I have problems in English writing, I } \\
\text { search for help in the corpus }\end{array}$ & 0 & 0 & 0 & 27.9 & 70.5 & 0 & 0 \\
\hline $\begin{array}{l}\text { When I search for information in the corpus, I } \\
\text { usually get the information that I need }\end{array}$ & 0 & 0 & 14.8 & 19.7 & 47.5 & 0 & 16.4 \\
\hline $\begin{array}{l}\text { I use the corpus when writing papers for other } \\
\text { course too }\end{array}$ & 0 & 0 & 0 & 0 & 59 & 39.3 & 0 \\
\hline $\begin{array}{l}\text { As I have learned more about the corpus, I have } \\
\text { come to like them more }\end{array}$ & 0 & 0 & 0 & 24.6 & 55.7 & 18 & 0 \\
\hline $\begin{array}{l}\text { I will use the corpus for my English writing in } \\
\text { the future }\end{array}$ & 0 & 0 & 0 & 0 & 32.8 & 65.6 & 0 \\
\hline
\end{tabular}


The effect of using a corpus on Iranian EFL learners' writing: Focus on grammatical accuracy and attitude

Table 5 ... continued

\begin{tabular}{|c|c|c|c|c|c|c|c|}
\hline Items & 1 & 2 & 3 & 4 & 5 & 6 & $\mathrm{~N}$ \\
\hline $\begin{array}{l}\text { Learning about the corpus has increased my } \\
\text { confidence about writing in English }\end{array}$ & 0 & 0 & 0 & 36.1 & 39.3 & 0 & 23 \\
\hline $\begin{array}{l}\text { If I had used the corpus earlier, I would have } \\
\text { had a better performance on exams }\end{array}$ & 0 & 0 & 0 & 34.4 & 63.9 & 0 & 0 \\
\hline $\begin{array}{l}\text { Overall, the corpus is a very useful resource for } \\
\text { my English writing }\end{array}$ & 0 & 0 & 0 & 16.4 & 82 & 0 & 0 \\
\hline $\begin{array}{l}\text { Corpus use is more helpful for writing than for } \\
\text { reading in English }\end{array}$ & 0 & 0 & 0 & 0 & 60.7 & 0 & 37.7 \\
\hline $\begin{array}{l}\text { Corpus use is more helpful for reading than for } \\
\text { writing in English }\end{array}$ & 0 & 0 & 24.6 & 26.2 & 0 & 0 & 47.5 \\
\hline $\begin{array}{l}\text { The corpus should be introduced in all EFL } \\
\text { writing courses }\end{array}$ & 0 & 0 & 0 & 0 & 50.8 & 47.5 & 0 \\
\hline $\begin{array}{l}\text { I recommend using the corpus in the same } \\
\text { course in future quarters }\end{array}$ & 0 & 0 & 0 & 0 & 29.5 & 68.9 & 0 \\
\hline $\begin{array}{l}\text { Corpus use should be taught in English classes } \\
\text { in my home country }\end{array}$ & 0 & 0 & 0 & 0 & 57.4 & 41 & 0 \\
\hline $\begin{array}{l}\text { I will recommend the corpus to other institutes' } \\
\text { and universities' students }\end{array}$ & 0 & 0 & 0 & 0 & 59 & 39.3 & 0 \\
\hline
\end{tabular}

Note. Values are in percentage.

For overall evaluations of corpus use in L2 writing, the students were asked whether they would recommend using the corpus to others. As seen in Table 4.5, all the participants agreed, with some enthusiasm, that corpus use should be introduced to students in their home country as well as in EFL writing courses.

To start with the helpfulness of using corpus in solving the problems, there was 70 percent of agreement. Although, there was a lack of knowledge in using corpus at the beginning of the course, learners showed an enthusiasm in using the search technique for their future writings by themselves, most of the participants noted strongly disagreement $(6=65.6 \%)$. Confidence is one of the important factors in L2 learning, to consider the result of the questionnaire, learners showed agreement and somewhat agreement in increasing their confidence about English writing by using the corpus (39 and 36 percent respectively). Also, 23 percent of the participants had no idea about this matter. The degree of agreement in introducing corpus in all EFL writing courses $(5=$ $50.8 \%$ and $6=47.5 \%$ ), revealed a great enthusiasm of the learners about this corpus.

To consider the above table for total evaluation in using corpus, there was a significantly positive attitude toward using corpus and it is remarkable that participants agreed and recommended the corpus to be used in all writing courses and even institutes' and universities' writing courses.

\subsection{Finding of the Third Research Question}

The third question posed in this study addressed the difference between the effectiveness of using corpus vs. dictionary on grammatical accuracy of students' writing ability. To find the answer of this question, the second hypothesis was formulated as below:

Hypothesis 2: There is no significant difference between the effects of using corpus vs, dictionary on Iranian EFL learners' grammatical accuracy in writing.

In order to investigate this hypothesis, independent-sample t-test was run to compare obtained scores of both experimental groups' participants in post-test sessions. The following tables will reveal the results of this comparison. 
Khalili, E., \& Rezvani, E.

\section{Table 6}

Independent-sample T-test Comparing Post-test Scores of the First and Second Experimental Groups

\begin{tabular}{llccc}
\hline \multicolumn{1}{c}{ Test } & $N$ & Mean & $S D$ & Std. Error Mean \\
\hline Second Experimental Post-test & 30 & 15.47 & 1.20 & .15 \\
First Experimental Post-test & 30 & 16.95 & 1.15 & .14 \\
\hline
\end{tabular}

Table 6, indicates that there was a significant difference between participants' scores obtained from post-test sessions in both experimental groups, according to the mean scores of the learners $\left(2^{\text {nd }} E M=15.47,1^{\text {st }} E M=\right.$ 16.95). It also can be concluded from the probability value (sig. $(2$-tailed) $=.000)$ which is below .05 .

As it is seen, participants of the first experimental group who used Grammaly corpus as a reference tool performed better in the post-test session. With respect to the corpus results, the participants especially liked using the corpus to monitor their writing and see whether their linguistic choices and collocates were correct. In another words, although the results indicates that a dictionary is useful for acquiring the meaning of words, a corpus is more useful for learning how and where to put words in context. Perhaps more importantly, they all indicated that the corpus use contributed to increased confidence about L2 writing.

\section{Discussions and Conclusions}

This study was conducted in order to investigate whether using corpus effects on Iranian English learners' grammatical accuracy in writing and discovers their attitude toward using corpus. In addition, the present study investigated which of the two writing methods, i.e. using corpus or dictionary can impact and improve writing ability of the learners. To do so, participants were divided into two experimental groups. In order to collect data, pre- and post-writing test were administered and a questionnaire was conducted in order to examine learners' attitude.

Writing can be a slow, painful process even in our mother tongue, but when it is in a second language the problems (and the pain) are magnified. Given the amount of conscious effort involved in the writing process, learners in the classrooms understandably expect feedback on their work and may feel discouraged if it is not provided. The difficulty for the teacher, however, is in balancing the needs of individual students for meaningful feedback with the unfortunate reality of ever-increasing workloads (Hedge, 1988).

Writing may be the most difficult task for some students of foreign languages. Through the act of writing itself, ideas are explored, clarified, and reformulated and, as this process continues, new ideas suggest themselves and become assimilated into the developing pattern of thought. Understanding that writing may be recursive, non-linear, and complicated, writers are able to adopt or even discard chunks of discourse or original plans as they review their writing, reconsider its function, and distance themselves from it in order to meet their readers' expectations (Zamel, 1983). Writing allows learners to employ their linguistic resources.

By making nonthreatening but challenging writing experiences for students, we are enabling them to improve confidence in the writing abilities they already have as they demonstrate--for self as well as teacher--the syntactic fluency they have been developing through a lifetime of using and listening to their native tongue. Very few if any of them could explain that they are putting words together in the patterns that create meaning; and as they fill the empty pages, they would be unable to understand and name the sorts of verbal constructs they're using to express their thoughts. But they are indeed demonstrating that they have already mastered the basic grammatical structures they need for writing and the writing we're asking them to do is enabling them to develop more fluency (Raimes, 1987).

Corpus use provided the participants with not only textual help but also with a psychological advantage in writing. The corpus instructed them on correct common usage, and it enhanced their confidence about their writing. This indicates a psychological, emotive aspect to learning, as learning requires a broad cognitive 
The effect of using a corpus on Iranian EFL learners' writing: Focus on grammatical accuracy and attitude approach taking into account affective issues as well (Gardner \& MacIntyre, 1992).

The study found that when the students accepted the new technology into their storage of L2 learning and writing, its effect went beyond its usefulness as an immediate linguistic checker. This study revealed the various roles corpora can play in language learning. One role is to increase awareness of word usage in contexts, rather than over-emphasizing "single words out of context" (McCarthy, 2001, p.63).

\section{References}

Biber, D. (2001). Using corpus-based methods to investigate grammar and use: Some case studies on the use of verbs in English. In R. Simpson, \& J. Swales (Eds.), Corpus linguistics in North America: Selections from the 1999 symposium (pp. 101-115). Ann Arbor: University of Michigan Press.

Biber, D., \& Conrad, S. (2001). Quantitative corpus-based research: Much more than bean counting. TESOL Quarterly, 35(2), 331-336. https://doi.org/10.2307/3587653

Bowker, L. (1998). Using specialized monolingual native-language corpora as a translation resource: A pilot study. Meta: Translators' Journal, 43(4), 631-651. https://doi.org/10.7202/002134ar

Cobb, T. (1997). Is there any measurable learning from hands on concordancing? System, 25(3), 301-315. https://doi.org/10.1016/S0346-251X(97)00024-9

Conrad, S. (2000). Will corpus linguistics revolutionize grammar teaching in the 21st century? TESOL Quarterly, 34, 548-560. https://doi.org/10.2307/3587743

Cope, B., \& Kalantzis, M. (2000). Multiliteracies: Literacy learning and the design of social futures. Psychology Press.

Flowerdew, J. (1996). Concordancing in language learning. In M. Pennington (Ed.), The power of CALL (pp. 97-113). Houston: Athelstan.

Flowerdew, J. (2002). Genre in the classroom: A linguistic approach. In A. M. Johns (Ed.). Genre in the Classroom: Multiple Perspectives (pp.91-104). London, UK: Lawrence Erlbaum associates.

Frankenberg-Garcia, A. (2012). Learners' use of corpus examples. International Journal of Lexicography, 25(3), 273-296. https://doi.org/10.1093/ijl/ecs011

Gardner, R. C., \& MacIntyre, P. D. (1992). A student's contributions to second language learning. Part I: Cognitive variables. Language teaching, 25(4), 211-220. https://doi.org/10.1017/S026144480000700X

Granath, S. (2009). Who benefits from learning how to use corpora? In K. Aijmer (Ed.), Corpora and language teaching (pp. 47-65). Amsterdam. Netherlands: John Benjamins. https://doi.org/10.1075/scl.33.07gra

Halliday, M. A. (1992). Language as system and language as instance: The corpus as a theoretical construct. Directions in Corpus Linguistics, 3(2), 61-77. https://doi.org/10.1515/9783110867275.61

Hedge, J. W., \& Kavanagh, M. J. (1988). Improving the accuracy of performance evaluations: Comparison of three methods of performance appraiser training. Journal of Applied Psychology, 73(1), 68-80. https://doi.org/10.1037/0021-9010.73.1.68

Hockey, S. (2001). Concordance programs for corpus linguistics. In R. C. Simpson \& J. M. Swales (Eds.), Corpus linguistics in North America: Selections from the 1999 symposium (pp. 76-97). Ann Arbor: University of Michigan Press.

Huang, Z. P. (2014). The effects of paper-based DDL on the acquisition of lexico-grammatical patterns in L2 writing. ReCALL, 26, 163-183. https://doi.org/10.1017/S0958344014000020

Hyland, K. (2003). Second language writing. Cambridge: Cambridge University Press. https://doi.org/10.1017/CBO9780511667251

Jabbour, G. (2001). Lexis and grammar in second language reading and writing. In D. Belcher, \& Hirvela, A. (Eds.), Linking literacies: perspectives on L2 reading writing connections (pp. 291-308). Ann Arbor: University of Michigan Press.

Johns, T. (1994). From printout to handout: Grammar and vocabulary teaching in the context of data-driven learning. In T. Odlin (Ed.), Perspectives on pedagogical grammar (pp. 293-313). Cambridge: Cambridge University Press. https://doi.org/10.1017/CBO9781139524605.014 
Khalili, E., \& Rezvani, E.

Kasper, L. F. (2000). New technologies, new literacies: Focus discipline research and ESL learning communities. Language Learning \& Technology, 4(2), 105-128.

Kennedy, C., \& Miceli, T. (2001). An evaluation of intermediate students' approaches to corpus investigation. Language Learning \& Technology, 5(3), 77-90.

McCarthy, J. F. (2001). The virtual world gets physical: Perspectives on personalization. IEEE Internet Computing, 5(6), 48-53. https://doi.org/10.1109/4236.968831

Murray, D. E. (2000) Changing technologies, changing literacy communities? Language Learning and Technology, 4(2), 43-58.

Raimes, A. (1987). Language proficiency, writing ability, and composing strategies: A study of ESL college student writers. Language Learning, 37, 439-467. https://doi.org/10.1111/j.1467-1770.1987.tb00579.x

Richards, C. (2000) Hypermedia, Internet communication and the challenge of redefining literacy in the electronic age. Language Learning and Technology, 4(2), 59-77.

Simpson, R. \& Swales, J. (2001). Corpus linguistics in North America. Ann Arbor: University of Michigan Press. https://doi.org/10.3998/mpub.11411

Sinclair, J. (1991). Corpus, concordance, collocation. Oxford, UK: Oxford University Press.

Sun, Y.-C. (2000). Using on-line corpus to facilitate language learning. Paper presented at the Annual Meeting of the Teachers of English to Speakers of Other Languages, British Columbia, Canada.

Tao, H. (2001). Discovering the usual with corpora: The case of remember. In R. Simpson \& J. Swales (Eds.), Corpus linguistics in North America: Selections from the 1999 symposium (pp. 116-144). Ann Arbor: University of Michigan Press.

Thornbury, S. (2002). How to teach vocabulary. London: Longman.

Thurstun, J., \& Candlin, C. (1998). Concordancing and the teaching of the vocabulary of academic English. English for Specific Purposes, 17(3), 267-280. https://doi.org/10.1016/S0889-4906(97)00013-6

Warschauer, M. (1999). Electronic literacies. Language, culture and power in online education. Mahwah, NJ: Lawrence Erlbaum Associates.

Watson Todd, R. (2001) 'Induction from self-selected concordances and self-correction. System, 29, 91-102. https://doi.org/10.1016/S0346-251X(00)00047-6

Yoon, H. (2008). More than a linguistic reference: The influence of corpus technology on L2 academic writing. Language Learning \& Technology, 12(2), 31-48.

Yoon, H., \& Hirvela, A. (2004) ESL student attitudes toward corpus use in L2 writing. Journal of Second Language Writing, 13(4), 257-283. https://doi.org/10.1016/j.jslw.2004.06.002

Zamel, V. (1983). The composing processes of advanced ESL students: Six case studies. TESOL Quarterly, 17(2), 165-187. https://doi.org/10.2307/3586647 